\title{
PRECEDENTES NO CÓDIGO DE PROCESSO CIVIL DE 2015: OBSTÁCULOS PARA SEU USO ADEQUADO E SUSTENTÁVEL ${ }^{1}$
}

\author{
Magno Federici Gomes* \\ Letícia Alves de Oliveira**
}

SUMÁRIO: Introdução; 1.1 Precedentes no Código de Processo Civil de 2015; 1.2 Formação dos precedentes: Ratio Decidendi e Obter Dictu; 1.3 Aplicação dos precedentes; 1.3.1 Da fundamentação e do princípio do contraditório; 1.3.2 Princípio da colegialidade; 1.3.3 Do julgamento liminar; 1.4 Distinção e superação de precedentes: Distinguishing e Overruling; 1.4.1 Modulação de efeito; 2 Problemas referentes ao uso dos precedentes; 2.1 Superficialidade da fundamentação dos julgados e propensões cognitivas; 2.2 Pseudocolegialidade; 3 Considerações finais; Referências.

RESUMO: O presente estudo busca discutir os precedentes judiciais enquanto meio para a razoável duração do procedimento, resguardando a qualidade das decisões judiciais. Observa-se a grande importância da interpretação na formação e na aplicação dos precedentes e do respeito ao princípio do contraditório, ao dever de fundamentação e ao princípio da colegialidade no uso dos precedentes. Percebemse questões prejudiciais para o bom julgamento que persistem no direito brasileiro, que o Código de Processo Civil de 2015 tem por objetivo combater. Utilizou-se no trabalho a metodologia teórica-documental, com raciocínio dedutivo. Conclui-se que os precedentes judiciais, se utilizados de maneira adequada e com respeito às balizas legais, são aptos para realizar os fins a eles destinados.

PALAVRAS-CHAVE: Precedentes judiciais; Interpretação na formação e na aplicação dos precedentes; Princípio do contraditório; Dever de fundamentação; Princípio da colegialidade.

\footnotetext{
${ }_{1}^{1}$ Trabalho financiado pelo edital $n^{0}$ 05/2016 (Projeto ${ }^{\circ}$ FIP 2016/11173-S2) do FIP/PUC, resultante dos Grupos de Pesquisas (CNPq): Regulação Ambiental da Atividade Econômica Sustentável (REGA), NEGESP e CEDIS (FCT-PT).

" Pós-doutor em Direito Público e Educação pela Universidade Nova de Lisboa-Portugal. Docente do Mestrado Acadêmico em Direito Ambiental e Desenvolvimento Sustentável na Escola Superior Dom Helder Câmara. Docente Adjunto da PUC Minas e Docente Titular licenciado da Faculdade de Direito Arnaldo Janssen. Brasil

** Graduanda em Direito pela PUC Minas. Brasil. E-mail: leticiaalvesdeoliveira3@gmail.com
} 


\title{
PRECEDENTS IN THE 2015 CODE OF CIVIL PROCEDURES: IMPAIRMENTS FOR ITS PROPER AND SUSTAINABLE USE
}

\begin{abstract}
Current analysis investigates the juridical precedents as a means for a reasonable duration of procedure while safeguarding the quality of juridical decisions. The importance of interpretation in the formation and application of precedents and of the principle of contradiction, the duty to ground one's arguments and the principle of collegiality in the use of precedents should be underscored. Pre-juridical issues for good judgment persisting in Brazilian law, in which the 2015 Civil Procedure Code should strive against, should be focused. Theoretical and documentary methodology was employed, coupled to deduction. Results show that juridical precedents, employed adequately and based on legal grounds, are proper to reach ends to which they have been aimed.
\end{abstract}

KEY WORDS: Juridical precedents; Interpretation in the formation and application of precedents; The Principle of contradiction; Fundaments; Principle of collegiality.

\section{PRECEDENTES EN EL CÓDIGO DE PROCESO CIVIL DE 2015: OBSTÁCULOS PARA SU USO ADECUADO Y SUSTENTABLE}

RESUMEN: En el presente estudio se busca discutir los precedentes judiciales como medio a la razonable duración del procedimiento, resguardando la calidad de las decisiones judiciales. Se observa la gran importancia de la interpretación en la formación y en la aplicación de los precedentes y del respeto al principio del contradictorio, al deber de fundamentación y al principio de la colegialidad en el uso dos precedentes. Se perciben cuestiones prejudiciales para el buen juzgamiento que persisten en el derecho brasileño, que el Código de Proceso Civil de 2015 tiene por objetivo combatir. Se utilizó en el estudio la metodología teórica-documental, con raciocinio deductivo. Se concluye que los precedentes judiciales, se utilizados de manera adecuada y con respeto a las balizas legales, son aptos para realizar los fines a ellos destinados.

PALABRAS CLAVE: Precedentes judiciales; Interpretación en la formación y en la aplicación de los precedentes; Principio del contradictorio; Deber de fundamentación; Principio dela colegialidad. 


\section{INTRODUÇÃO}

Os precedentes judiciais, como apontamento do entendimento correto e mais adequado aos órgãos judiciários, oferecem inúmeros benefícios para o bom julgamento e para o aproveitamento da atividade processual. $\mathrm{O}$ instituto consiste em um dos caminhos para a duração razoável do procedimento, objetivo tão almejado pelo Poder Judiciário brasileiro, diante do expressivo número de processos que tramitam hoje em dia. No entanto, diversos são os desafios enfrentados para uma adequada aplicação dos precedentes no Brasil, o que acarreta o afastamento dele de seus objetivos precípuos. Além disso, a inadequada aplicação dos precedentes provoca inúmeras consequências nocivas para a atividade jurisdicional, que prejudicam a correta aplicação do direito e causam incongruências em torno das decisões judiciais.

O problema que se pretende responder é como solucionar as práticas viciadas de superficialidade da fundamentação, de propensões cognitivas e de pseudocolegialidade, derivadas da tentativa de otimização numérica absoluta das decisões por meio dos precedentes, sem prejuízo da sustentabilidade judicial.

Com isso, o objetivo desse estudo é discutir as questões prejudiciais à atividade jurisdicional em torno dos precedentes, ora supramencionadas. Busca-se, então, compreender os meios para combater tais dilemas.

Utilizou-se no trabalho a metodologia teórica-documental, com técnica dedutiva e consulta as fontes bibliográficas, tendo como marco teórico a obra de Theodoro Júnior e outros ${ }^{04}$.

Os precedentes passaram por uma evolução histórica e um aprimoramento, principalmente com a aproximação entre as tradições do civil law e commom law. Atualmente, demandam certa atenção tanto em sua formação, quanto em sua aplicação, para atingirem os fins a eles destinados. E ainda enfrentam alguns desafios relacionados ao seu uso adequado.

\subsection{PRECEDENTES NO CÓDIGO DE PROCESSO CIVIL DE 2015}

Observa-se no mundo contemporâneo uma aproximação mútua entre as tradições do civil law e do common law. No Brasil há um movimento de conver-

$\overline{04}$ THEODORO JÚNIOR, Humberto; et al. Novo CPC: fundamentos e sistematização. 2. ed. Rio de Janeiro: Forense, 2015. 
gência entre as tradições do civil law com o common law, e seu uso de precedentes, denominado por Streck de "commonlização", conduzido pelo fortalecimento do uso das decisões passadas dos Tribunais como fundamento para as decisões judiciais. Além disso, esse movimento é devido "a existência de controle difuso de constitucionalidade, o emprego crescente de textos redigidos a partir de técnica legislativa aberta e, sobretudo, uma nova compreensão a respeito do significado da interpretação jurídica" ${ }^{05}$.

A interpretação jurídica, que tem caráter indispensável para a correta aplicação do direito ao caso concreto, se torna ainda mais importante na aplicação de precedentes. Estes que não podem ser utilizados indistintamente e nem em confronto com o caso que lhe deu origem. Fundamentalmente, cabe à interpretação propiciar à decisão judicial a prevalência do entendimento mais adequado sobre a norma a ser aplicada.

Deste modo, as decisões judiciais são extremamente importantes para toda a sociedade e para seu futuro, e por isso devem ser tomadas com cautela e ser fruto de intensa e cuidadosa intepretação dos magistrados. Nesse sentido, Iocohama, Bruno e Bergamaschi destacam

[...] é preciso que ele sempre decida como se estivesse a campo, pois, à medida que o juiz proporcione a adaptação da norma às peculiaridades de cada caso com essa visão, de consequência, estará garantindo uma possível aplicação justa do Direito, despertando nos indivíduos uma maior confiança no Poder Judiciário pela realidade espelhada no resultado da tutela jurisdicional ${ }^{06}$.

Marinoni, Arenhart e Mitidiero enfatizam que o texto se distingue da norma e que a norma é resultado da interpretação ${ }^{07}$. A partir dessa compreensão entendese que a solução de um caso concreto não é a única função da decisão judicial, mas também um meio para promoção da unidade do direito. Dar unidade ao direito é tarefa das denominadas Cortes Supremas, Supremo Tribunal Federal (STF) e Superior Tribunal de Justiça (STJ), a partir da solução de casos que sirvam como precedentes para guiar a interpretação futura do direito pelos demais juízes, promovendo a segu-

\footnotetext{
${ }^{05}$ MARINONI, Luiz Guilherme; ARENHART, Sérgio Cruz; MITIDIERO, Daniel. Novo curso de processo civil: tutela dos direitos mediante procedimento comum. 2. ed. São Paulo: Revista dos Tribunais, 2016. v. 2, p. 640.

${ }^{06}$ IOCOHAMA, Celso Hiroshi; BRUNO, Camila Kienen; BERGAMASCHI, Joice Duarte Gonçalves. O escopo educativo do processo e a educação da sociedade por meio da tutela jurisdicional. Revista Jurídica Cesumar, Maringá - PR, v. 17, n. 1, p. 11-41, jan./abr. 2017, p. 36.

${ }^{07}$ MARINONI, Luiz Guilherme; ARENHART, Sérgio Cruz; MITIDIERO, Daniel. Op. cit., p. 640.
} 
rança na ordem jurídica. Já uniformizar é uma tarefa que se diferencia da anterior, e é conferido às Cortes de Justiça, Tribunais Regionais Federais e Tribunais de Justiça o dever de controlar a justiça da decisão de todos os casos a eles dirigidos, incluindo o dever de aplicação isonômica do direito. Portanto, se não há precedentes formados pelas Cortes Supremas, se torna inevitável o desacordo interpretativo das normas.

No art. 926 do Código de Processo Civil de 2015 (CPC/2015) se evidencia o dever do STF e do STJ de dar unidade ao direito. E o dever dos Tribunais Regionais Federais e dos Tribunais de Justiça de controlar a uniforme aplicação dos precedentes, constitucionais e federais. No entanto, o legislador não faz essa distinção das funções das cortes judiciárias no termo jurisprudência. Como se observa no

Art. 926 do CPC/2015. Os tribunais devem uniformizar sua jurisprudência e mantê-la estável, íntegra e coerente.

$\S 1^{\circ} \mathrm{Na}$ forma estabelecida e segundo os pressupostos fixados no regimento interno, os tribunais editarão enunciados de súmula correspondentes a sua jurisprudência dominante.

$\S 2^{\circ}$ Ao editar enunciados de súmula, os tribunais devem ater-se às circunstâncias fáticas dos precedentes que motivaram sua criaçã $0^{08}$.

Ainda no referido artigo observa-se a aparente indistinção entre os termos súmula e precedentes. Por isso, se faz necessária a distinção entre jurisprudência, súmulas e precedentes, pois o legislador ressignificou os conceitos dos dois primeiros e introduziu o último no $\mathrm{CPC} / 2015$.

A jurisprudência, por ser uma interpretação da lei na solução de casos, é desempenhada pelas Cortes de Justiça. Gorla, Taruffo e Motta expõem o conceito tradicional de jurisprudência, e sua importância, como "a interpretação da lei desempenhada pelas cortes para solução de casos, cuja múltipla reiteração gera uniformidade capaz de servir de parâmetro de controle, não gozando de autoridade formalmente vinculante" ${ }^{\text {"09 }}$.

As súmulas, que têm por objetivo auxiliar na interpretação e na aplicação do direito de ambas as Cortes, podem emanar de quaisquer das Cortes. Theodoro Júnior e outros citam o conceito de enunciado de súmula, como: "pronunciamentos dos Tribunais vocacionados à abstração e à generalidade, tais quais as leis, e de que

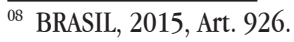

${ }^{09}$ GORLA, Gino. Diritto comparato e diritto comune europeo. Milano: Giuffrè Editore, 1981, p. 265. No mesmo sentido: TARUFFO, Michele. Precedente e giurisprudenza. Rivista Trimestrale di Diritto e Procedura Civile, v. 61, n. 3, p. 709-725, set. 2007; MOTTA, Otávio. Precedente e jurisprudência no estado constitucional brasileiro. In: MITIDIERO, Daniel. O processo civil no Estado Constitucional. Salvador: Jus Podium, 2012, p. 263.
} 
sua aplicação poderia se dar desligada dos casos que deram base a sua criação"10. Através do art. 927 incisos II e IV do CPC/2015, percebe-se a importância das súmulas como guias para a interpretação do direito, e o art. 926, $\S 2^{\circ}$, prevê o dever de identificação e de congruência das súmulas com as circunstâncias fáticas dos casos que motivaram suas criações. Assim, o sentido das súmulas apenas pode ser interpretado a partir de uma comparação entre os casos que originaram a súmula e o novo caso em análise, e suas hipóteses fáticas.

O novo CPC/2015 introduz o conceito de precedentes como sendo razões generalizáveis extraídas de decisões, ou seja, fatos jurídicos considerados relevantes na análise do caso examinado e que determinaram a decisão proferida. Os precedentes são formados apenas pelas Cortes Supremas e são sempre obrigatórios, isto é, vinculantes. MacCormick e Summers afirmam que: "Precedentes são decisões anteriores que funcionam como modelos para decisões futuras. Aplicam-se as lições do passado para resolver problemas do presente e do futuro, constituindo uma parte fundamental da razão prática humana"11.

Deve-se perceber o caráter meramente exemplificativo do art. 927 do CPC/2015, uma vez que apenas os incisos I e III, precedentes firmados em controle concentrado e os estabelecidos em julgamento de recursos extraordinário e especial repetitivos, tratam de precedentes das Cortes Supremas. Ou seja, tal artigo traz alguns exemplos de precedentes e incidentes de natureza erga omnes, que devem ser observados pelos juízes e tribunais.

\subsection{FORMAÇÃO DOS PRECEDENTES: RATIO DECIDENDI E OBTER DICTUM}

Os precedentes são formados a partir de decisões judiciais, mas nem toda decisão judicial se torna um precedente ${ }^{12}$, como enfatizam Marinoni, Arenhart e Mitidiero. O que torna uma decisão capaz de gerar um precedente são as razões constantes na justificação, identificáveis no caso exposto no relatório do processo. $O$ precedente pode ser identificado na ratio decidendi de um caso analisado, considerado por Nunes como "(elemento vinculante) justifica e pode servir de padrão

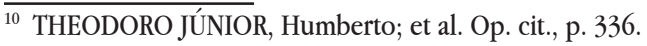

${ }^{11}$ MACCORMICK, Neil; SUMMERS, Robert S.; Introduction. In: MACCORMICK, Neil; SUMMERS, Robert S. Interpreting precedents: a comparative study. Aldershot: Ashgate, 1997. Cap. 1, p. 01.

${ }^{12}$ MARINONI, Luiz Guilherme; ARENHART, Sérgio Cruz; MITIDIERO, Daniel. Op. cit., p. 651. 
para a solução do caso futuro"13. Ou seja, questões relevantes constantes no caso, necessárias e suficientes para a solução do mesmo.

A ratio decidendi se diferencia da fundamentação, pois a primeira relaciona-se à unidade do direito, e a segunda ao caso particular. Mas tanto a ratio quanto a fundamentação são formadas a partir da justificação.

No entanto, nem todo o conteúdo da justificação poderá ser utilizado para a formação do precedente, a saber, proposições não necessárias para a solução do caso, denominadas de obter dictum, que é aquilo sem referência ao caso, ou com referência, mas não contribui para a solução do mesmo. Um aspecto relevante, mas sem relação de causalidade ao caso. Assim, a parte da decisão considerada ratio decidendi seria um precedente "vinculativo" e a considerada obter dictum um precedente "persuasivo".

O conceito de precedente é material e qualitativo, apesar da sensação que o art. 927 do CPC/2015 provoca que os precedentes sejam formados apenas por súmulas, recursos repetitivos, assunção de competências e orientação de plenário ou órgão especial, ou seja, uma noção formal e quantitativa. Essa noção material e qualitativa deve-se ao fato de que as justificações utilizadas, que serão analisadas por inteiro, mostram-se necessárias e suficientes para influir na solução da questão examinada, e por estar relacionada à autoridade conferida das Cortes que os formam.

Assim, podem gerar precedentes as razões invocadas no julgamento de recursos repetitivos ou no julgamento do incidente de assunção de competência, pelas Cortes Supremas, STF e STJ. Mas também no julgamento de recurso extraordinário ou de recurso especial. E ainda poderão existir, por meio de pronunciamentos sobre direito local, precedentes oriundos do Tribunal de Justiça, Corte de Justiça, que valerão para os juízes a ele submetidos, e de seus julgamentos, que configurarão precedente local, independente de serem sumulados.

\subsection{APLICAÇÃO DOS PRECEDENTES}

Ao se aplicar um precedente é indispensável à interpretação do caso e das razões empregadas para a sua solução. Assim, o juiz deve analisar o caso e então avaliar a pertinência da possível aplicação do precedente.

\footnotetext{
${ }^{13}$ NUNES, Dierle José Coelho. Processualismo constitucional democrático e o dimensionamento de técnicas para a litigiosidade repetitiva: a litigância de interesse público e as tendências 'não compreendidas' de padronização decisória. Revista de Processo, São Paulo, v. 199, nº 36, p. 41-82, set. 2011, p. 48.
} 
Na aplicação de um precedente é possível que os juízes deem novos sentidos ao texto devido à própria noção sobre o significado de precedente, uma atividade reconstrutiva do passado ${ }^{14}$ como salientam Theodoro Junior e outros. Assim, se possibilitam as distinções (distinguishing), ampliações (widening) e reduções (narrowing), dos precedentes para a melhor adequabilidade ao caso, a partir das circunstâncias de identificação entre os casos, uma vez que não é possível que o legislador produza normas perfeitas, que se adéquem e abarquem soluções para toda e qualquer situação fonte de conflito. Os precedentes têm como objetivo indicar o entendimento correto, mais adequado, aos órgãos judiciários para a solução dos casos. E para isso, é imprescindível a comparação entre os casos, o novo em análise e o que originou o precedente que poderá ser aplicado.

\subsubsection{Da fundamentação e do princípio do contraditório}

$\mathrm{O}$ art. 489 do $\mathrm{CPC} / 2015$ dispõe sobre os requisitos das sentenças, e em seu $\S 1^{\circ}$ determina que os Tribunais, ao aplicarem precedentes, observem o direito ao contraditório e o dever de fundamentação. Ou seja, o direito ao debate entre as partes sobre a aplicação do precedente, inclusive as questões de conhecimento oficioso, evitando o fenômeno intitulado "decisão surpresa" que pode atribuir nulidade à decisão, por desatender ao princípio do contraditório. Deste modo, o processo não será formado por atos isolados dos sujeitos processuais, mas será fruto da comparticipação entre eles. Como alertam Theodoro Júnior e outros.

Toda vez que o magistrado não exercite ativamente o dever de advertir as partes quanto ao específico objeto relevante para o contraditório, o provimento deve ser invalidado, e a relevância ocorre se o ponto de fato ou de direito constitui necessária premissa ou fundamento para a decisão (ratio decidendi) ${ }^{15}$.

E o dever de fundamentação do magistrado consiste em expor de maneira precisa a identidade ou semelhança entre casos capazes de justificar a aplicação do precedente. Nesse sentido, Bahia alerta que "o juiz, assim, não pode ser só a boca da jurisprudência (como já o fora da lei, no tempo dos exegetas)"16. Ou seja, o juiz não

$\overline{14}$ THEODORO JÚNIOR, Humberto; et al. Op. cit., p. 346.

${ }^{15}$ Ibidem, p. 110.

${ }^{16}$ Nesse sentido: BAHIA, Alexandre Melo Franco. As Súmulas Vinculantes e a Nova Escola da Exegese. Revista de Processo, São Paulo, v. 206, p. 359-379, abr. 2012. 
pode apenas repetir ementas e trechos de julgados, sem devidamente fundamentar e explicitar a aplicabilidade do precedente ao caso analisado. Nesse sentido, Theodoro Júnior e outros consideram uma decisão fundamentada como

Percebe-se que, para que a decisão seja considerada fundamentada, da mesma forma que não basta apenas citação da lei, não basta a mera invocação de precedente ou súmula. O magistrado tem de mostrar de que forma estes se amoldam ao caso, o que significa aquele exercício hermenêutico [...] seja no caso do precedente, seja no de súmula, precisa haver o confronto entre questões de fato e de direito entre o paradigma e o caso sub judice. De outro lado [...] a decisão precisa enfrentar todas as teses que possam afetar seu julgamento, se a parte se fundar em súmula, jurisprudência ou precedente, o juiz tem de responder a essa questão ${ }^{17}$.

Portanto, o dever de fundamentação e o princípio do contraditório são correlatos e fundamentais para o bom julgamento, e a adequada aplicação dos precedentes depende, sobretudo, destes e da comparticipação entre sujeitos processuais.

\subsubsection{Princípio da colegialidade}

As cortes de precedente, STF e STJ, e as Cortes de Justiça, Tribunais Regionais Federais e Tribunais de Justiça são compostas por órgãos colegiados, ou seja, órgãos julgadores integrados por três ou mais ministros ou desembargadores. Tais órgãos são responsáveis pelos julgamentos das causas em que a Corte seja competente, e os recursos, que por regra são julgados por órgãos colegiados. Trocker enfatiza a importância do diálogo no processo que necessariamente "amplia o quadro de análise, constrange à comparação, atenua o perigo de opiniões preconceituosas e favorece a formação de um juízo mais aberto e ponderado"18.

O princípio do contraditório, já mencionado, não limita sua aplicação somente a decisões unipessoais, monocráticas, mas se destaca ainda mais na prolação de decisões colegiadas, por exemplo, na sustentação oral dos advogados nos recursos, que é extremamente relevante para a análise das peculiaridades do caso.

Anteriormente o debate em relação a teses conflitantes era incumbido às partes, para defender seus interesses, enquanto a preocupação do julgamento con-

\footnotetext{
$\overline{17}$ THEODORO JÚNIOR, Humberto; et al. Op. cit., p. 362.

${ }_{18}$ TROCKER, Nicolò. Processo civile e costituzione. Editora: A. Giuffrè, 1974, p. 645.
} 
sistia na solução do caso. Com a transformação da função das Cortes Supremas do civil law, tornou-se essencial para sua legitimação o fomento ao debate. Deste modo, há essa estimulação para aprofundamento "da deliberação em torno da solução das disputas interpretativas e consequente elaboração do precedente"19.

Além de influenciar o procedimento recursal, o fomento ao debate e à participação influencia o comportamento dos julgadores, que nesse ambiente desenvolvem uma nova perspectiva de sua responsabilidade. Diante de discussões e questionamentos tem-se a expectativa que o julgador colabore, por meio de seus argumentos, de maneira efetiva para decisão do órgão colegiado, uma vez que além da solução para o caso, poderá se elaborar um precedente.

No entanto, o dissenso entre os julgadores poderá causar um problema na formação do precedente. Pode ocorrer que em um julgamento, o foco seja transferido da solução do recurso para as razões determinantes do caso e sua interpretação. Nessa situação se houver uma divergência entre os julgadores em relação aos fundamentos, ou em firmar determinado entendimento, poderá se tornar incapaz de se formar um precedente mesmo que pudesse conduzir a uma solução favorável. Se a ênfase do julgamento for a resolução de caso, o desacordo consiste em um instrumento para o julgador acautelar o seu entendimento pessoal diante do entendimento da maioria. Deste modo: "A Corte, se tem a função de desenvolver o direito, deve deixar absolutamente claro à sociedade as razões pelas quais as normas que são expressas nas rationes decidendi dos precedentes não contam com a adesão de todos os membros do colegiado"20.

A ratio decidendi constitui um sentido do texto legal ou regra editada pela Corte, deste modo apenas poderá ser formada pela maioria do colegiado.

Por isso, não são todas as decisões recursais que poderão originar precedente, pois se torna impossível elaborar um precedente se nenhum fundamento foi compartilhado pela maioria dos membros do colegiado. Assim, o fundamento é extremamente importante para a decisão final e para a formação de precedentes, quando a Corte não tem apenas a função de resolver um conflito, mas também objetiva dar sentido ao direito, auxiliando a sua interpretação.

\footnotetext{
${ }^{19}$ MARINONI, Luiz Guilherme; ARENHART, Sérgio Cruz; MITIDIERO, Daniel. Op. cit., p. 653.

${ }^{20}$ Ibidem, p. 654.
} 


\subsubsection{Do julgamento liminar}

$\mathrm{O}$ art. 332 do CPC/2015 estabelece as possibilidades de extinção do processo por improcedência liminar do pedido, ou seja, liminarmente por ocorrer sem a oitiva da parte ré. Tais hipóteses extinguem o processo com resolução do mérito.

Art. 332 Nas causas que dispensem a fase instrutória, o juiz, independentemente da citação do réu, julgará liminarmente improcedente o pedido que contrariar:

I- Enunciado de súmula do Supremo Tribunal Federal ou do Superior Tribunal de Justiça;

II- Acórdão proferido pelo Supremo Tribunal Federal ou pelo Superior Tribunal de Justiça em julgamento de recursos repetitivos;

III- Entendimento firmado em incidente de resolução de demandas repetitivas ou de assunção de competência;

IV- Enunciado de súmula de Tribunal de Justiça sobre direito local.

§ 10 O juiz também poderá julgar liminarmente improcedente o pedido se verificar, desde logo, a ocorrência de decadência ou de prescrição ${ }^{21}$.

Observa-se, que é possível o julgamento liminar quando houver precedente ou jurisprudência contrária ao pedido, ou ainda quando o direito tiver sido extinto por decadência, ou a pretensão atingida por prescrição. Em se tratando de julgamento de improcedência liminar do pedido que contrariar jurisprudência das Cortes de Justiça, Tribunais de Justiça e Tribunais Regionais Federais, só é possível no caso de jurisprudência formada em incidente de resolução de demandas repetitivas ou incidente de assunção de competência.

O julgamento liminar aparentemente não levaria em consideração questões que o autor não teve oportunidade de se manifestar, assim ofenderia o princípio do contraditório estabelecido pelo art. $5^{\circ}$, inciso LV, da Constituição Federal de 1988: "aos litigantes, em processo judicial ou administrativo, e aos acusados em geral são assegurados o contraditório"22. E o art. 10 do CPC/2015: "O juiz não pode decidir, em grau algum de jurisdição, com base em fundamento a respeito do qual não se tenha dado às partes oportunidade de se manifestar"23.

No entanto, o contraditório poderá ser exercido eficazmente na apelação, e ainda o juiz poderá se retratar. Se "não interposta a apelação, o réu será intimado

\footnotetext{
$\overline{{ }^{21} \text { BRASIL, 2015, Art. } 332 .}$

${ }^{22}$ BRASIL, 1988, Art. $5^{\circ}$, inciso LV.

${ }^{23}$ BRASIL, 2015, Art. 10.
} 
do trânsito em julgado da sentença"² . Mas se interposta a apelação, o juiz poderá se retratar em cinco dias. Se retratando, o juiz determinará o prosseguimento do processo, com a citação do réu. Se o juiz não se retratar, determinará a citação do réu para oferecer contrarrazões, no prazo de cinco dias. E ainda caberá agravo interno, no caso de cumulação de pedidos, para a decisão parcial de improcedência liminar de um ou alguns pedidos.

\subsection{DISTINÇÃO E SUPERAÇÃO DE PRECEDENTES: DISTINGUISHING E OVERRULING}

As técnicas de distinção, distinguishing, e superação, overruling, são extremamente importantes e constituem "ferramentas básicas para a operação com precedentes" 25 .

Basicamente, o distinguishing consiste em uma distinção feita entre o caso em análise e o precedente invocado. E o overruling constitui uma superação da tese em que baseava aquele precedente. Essas técnicas "pertencem, há muito, à praxe forense de países de common law, nas quais juízes e advogados as utilizam para flexibilizar o enrijecimento que poderia advir do stare decisis" ${ }^{26}$, segurança jurídica e igualdade. Importante lembrar que tal sistema em que o Brasil se aproxima cada vez mais, e essa situação é considerada por alguns autores um movimento de convergência entre os sistemas.

$\mathrm{O}$ CPC/2015 em vários momentos exterioriza a necessidade de distinções entre os casos, em seus arts. $1029, \S 2^{\circ}$, e $1037, \S 9^{\circ}$. E ainda sobre a alteração ou modificação de precedentes, no art. $927, \S \S 3^{\circ}$ e $4^{\circ}$.

Ao se tentar aplicar um precedente se analisa a semelhança entre o caso analisado e o que deu origem ao precedente invocado, se envolve a mesma questão, ou ao menos se é semelhante, sendo a análise positiva se aplicará aquele precedente. No entanto, se a questão não for idêntica ou semelhante, haverá a distinção, distinguishing, entre o caso e o precedente, e este não poderá ser aplicado. A distinção deverá ser consistente, ocorrendo uma diferenciação entre as questões examinadas pelo órgão jurisdicional. No entanto existe a possibilidade de distinções inconsistentes, que ocorre quando o órgão jurisdicional nega em parte a aplicação daquele

\footnotetext{
${ }^{24}$ BRASIL, 2015, Art. 332, $\S 2^{\circ}$.

${ }^{25}$ MARINONI, Luiz Guilherme; ARENHART, Sérgio Cruz; MITIDIERO, Daniel. Op. cit., p. 659.

${ }^{26}$ THEODORO JÚNIOR, Humberto; et al. Op. cit., p. 362.
} 
precedente, e sem apresentar critérios seguros para isso. A distinção inconsistente é vedada no direito brasileiro. Marinoni, Arenhart e Mitidiero ainda consideram a distinção inconsistente "uma efetiva afronta ao precedente"

As técnicas de superação de precedentes fazem-se necessárias para desenvolver o direito, objetivando manter sua congruência social e coerência sistêmica, preservar a igualdade de todos e a proteção da confiança, diante da ordem jurídica. Para a doutrina, há uma norma básica pra superação de precedentes (basic overrunling principle), que consiste na junção entre a carência do precedente de congruência social e coerência sistêmica com os princípios básicos do stare decisis, segurança jurídica e igualdade, que não autorizariam a sua replicabilidade (replicability), devido a essa carência ${ }^{28}$. Para Theodoro Júnior e outros: "A aludida técnicas de overruling viabiliza a participação das partes na indução de que o tribunal se afaste de regras jurisprudenciais de modo legítimo (justified departures), e não afastamento subjetivos e desprovidos de embasamento" ${ }^{29}$.

A superação de precedentes poderá ser total ou parcial, sendo parcial poderá ser por meio da transformação (transformaion), ou reescrita (overriding). Quando não oportuna ou necessária à superação total far-se-á a superação parcial. A transformação ocorre sem negar formalmente o precedente, reconfigurando-o de maneira parcial, considerando aspectos fáticos-jurídicos que não foram encarados como relevantes na decisão do caso ou da questão jurídica anterior. Leia-se: "No mais das vezes, porém, a transformação equipara-se substancialmente à revogação total do precedente, com a única diferença de que com ele a Corte não anuncia expressamente a revogação" ${ }^{\text {". }}$.

E a reescrita objetiva restringir a aplicação do precedente, perdendo espaço de incidência. Deste modo, o precedente é reescrito, mas não é revogado totalmente.

A superação ainda poderá ser "precedida de audiências públicas e da participação de pessoas, órgãos ou entidades que possam contribuir para a rediscussão da tese" ${ }^{31}$, conforme art. $927, \S 2^{\circ}$, do CPC/2015. E observará a necessidade de "fundamentação adequada e específica, considerando os princípios da segurança

\footnotetext{
${ }^{27}$ MARINONI, Luiz Guilherme; ARENHART, Sérgio Cruz; MITIDIERO, Daniel. Op. cit., p. 660.

${ }^{28}$ Ibidem, p. 660.

29 THEODORO JÚNIOR, Humberto; et al. Op. cit., p. 129.

${ }^{30}$ EISENBERG, Melvin Aron. The nature of the common law. Cambridge, Mass, United States: Harvard University Press, 1991, p. 132-135.

${ }^{31}$ BRASIL, 2015, Art. 927, $\S 2^{\circ}$.
} 
jurídica, da proteção da confiança e da isonomia"32 , nos termos do art. $927, \S 4^{\circ}$, do CPC/2015.

A superação de precedentes costuma ser sinalizada (signaling) para comunicar a possível mudança de entendimento aos interessados, respeitando à segurança jurídica. E normalmente a eficácia da alteração do precedente para o futuro. Pode-se outorgar a eficácia ex nunc a essa alteração em relação ao precedente, para se resguardar a segurança e a igualdade.

\subsubsection{Modulação de efeitos}

$\mathrm{O}$ art. $927, \S 3^{\circ}$, do $\mathrm{CPC} / 2015$, de forma expressa autoriza a modulação de efeitos da decisão que revoga precedente, em nome do interesse social e da segurança jurídica. A modulação tem por objetivo evitar a insegurança jurídica que a mudança de um entendimento poderia causar na sociedade. A Corte Suprema, por atribuir sentido ao direito, constitui uma Corte de Precedentes, e tem o dever de zelar pela confiança conferida aos seus atos, podendo limitar os efeitos retroativos das decisões. Assim, é fundamental a análise da conjunção entre "o valor de afirmação do direito, contido na decisão revogadora, em face do valor da confiança justificada, depositado no precedente revogado"33 para então se avaliar a possibilidade de aplicação de efeitos retroativos à decisão que revoga um precedente.

Deste modo apenas será possível se aplicar um precedente revogado, em nome da segurança jurídica, quando algo houver se estabelecido no passado devido à justa confiança depositada naquele precedente. Mas não basta confiança, deve-se consistir em uma confiança justificada. Ou seja, "confiança qualificada por critérios que façam valer que o precedente racionalmente merecia confiança à época em que os fatos se passaram" ${ }^{\text {'4 }}$. Assim, critérios para a modulação de efeitos temporários do precedente se fundam onde se procura a confiança justificada, objetivando evitar a denominada "surpresa injusta".

Contudo, há a possibilidade de se conceder efeitos prospectivos para tutelar situações passadas que se formaram baseadas no precedente revogado, se este precedente tinha credibilidade quando foi revogado, ou no caso de processo que estiver em curso e em relação às situações judicializadas. Ou ainda no caso de situa-

\footnotetext{
$\overline{32}$ BRASIL, 2015, Art. $927, \S 4^{\circ}$.

${ }^{33}$ MARINONI, Luiz Guilherme; ARENHART, Sérgio Cruz; MITIDIERO, Daniel. Op. cit., p. 662.

${ }^{34}$ Ibidem, p. 663.
} 
ção de direito material que motivou a revogação for baseado em precedente com credibilidade.

Ou então, há a possibilidade de suspender os efeitos do novo precedente até determinada data, na hipótese do precedente modificar norma utilizada por tempo considerável. O objetivo é não surpreender todos que estejam habituados com o precedente revogado.

\section{PROBLEMAS REFERENTES AO USO DOS PRECEDENTES}

Os precedentes são extremamente relevantes e têm entre suas funções precípuas, que normalmente é a mais defendida, a finalidade de otimizar o julgamento de casos idênticos. No entanto, tal discurso relacionado à duração razoável do procedimento $^{35}$ induz a preocupantes questões, verdadeiros problemas em relação ao uso dos precedentes no Brasil. Com a aplicação de precedente dissociado do caso que lhe deu origem, tendo por objetivo apenas otimizar numericamente as decisões, infringe-se o dever de fundamentação previsto no art. 489, § $1^{\circ}$, do CPC/2015 ocorrendo o fenômeno da superficialidade da fundamentação dos julgados. O uso dos precedentes enfrenta, ainda, o desafio da pseudocolegialidade, decorrente da quantidade de processos nos tribunais, quando decisão que deveria ser colegiada é proferida pelo relator monocraticamente.

As pretensões relacionadas à aplicação dos precedentes não podem ser buscadas a qualquer custo, e nem em detrimento de outros princípios, mas devem ser interpretadas em harmonia com os demais princípios do modelo constitucional de processo.

\subsection{SUPERFICIALIDADE DA FUNDAMENTAÇÃO DOS JULGADOS E PROPENSÕES COGNITIVAS}

A indicação do entendimento mais adequado para a solução dos casos é objetivo principal dos precedentes, mas sua aplicação não pode se dar de maneira

\footnotetext{
35 Para aprofundamento na dimensão jurídico política do desenvolvimento sustentável e no direito à razoável duração do procedimento, como forma de se assegurar os direitos fundamentais intergeracionais, ver: GOMES, Magno Federici; FERREIRA, Leandro José. A dimensão jurídico-política da sustentabilidade e o direito fundamental à razoável duração do procedimento. Revista do Direito, Santa Cruz do Sul, n. 52, v. 2, p. 93-111, maio/set. 2017, p. 102-103 e 106-108.
} 
indiscriminada e sem respeito às balizas legais. Como já mencionado, são indispensáveis para se invocar um precedente o respeito ao princípio do contraditório e ao dever de fundamentação dos magistrados, dentre outros.

No entanto, apesar das previsões legais que estabelecem o uso adequado dos precedentes, ainda persistem condutas inadequadas e discutíveis por parte dos magistrados, causando a superficialidade da fundamentação dos julgados. Ao magistrado se faz necessária a paciência, sendo esta ativa para julgar com justiça. $\mathrm{O}$ julgar é um trabalho árduo, no qual condutas tendentes à facilitação do julgamento comprometem a sua justiça.

O CPC/2015, em decorrência dos comportamentos não cooperativos entre os sujeitos processuais e em prol do processo justo, democrático e sustentável, impõe a conduta leal e de boa-fé tanto das partes quanto do magistrado. O magistrado tem os deveres de esclarecimento, de diálogo, de prevenção e de auxílio para com os sujeitos interessados no processo, propiciando um ambiente de cooperação. E ainda há o dever de fundamentação adequada, bem como o princípio do contraditório, que impede a conduta recorrente dos magistrados de invocar um precedente sem reflexão e ausente a explicação sobre o motivo de sua incidência no caso, visando apenas otimizar numericamente as decisões, sem proporcionar o debate sobre a aplicação do precedente. No entanto, ainda permanecem condutas contrárias ao dever de fundamentação com bem enfatiza Oliveira.

A fundamentação das decisões se apresenta, cada vez mais, como uma tarefa menor, um trabalho incômodo e de pouco valor. Algo que ainda se tem de fazer em nome de um ritualismo meio caduco. Mas, de todo modo, algo que se pode deixar para fazer após a atividade de decidir" ${ }^{36}$.

Nesse sentido, a jurisdição sustentável aponta que

$\mathrm{Na}$ construção da decisão ideal para o caso concreto, o desafio hermenêutico da jurisdição não é mais um singelo exercício de subsunção do fato à norma, mas sim uma intensa atividade de construção e ponderação, participativa e dialética, que considera os imprescindíveis aportes transdiciplinares e que projeta cautelosamente os efeitos e as consequências da decisão para o futuro ${ }^{37}$.

\footnotetext{
${ }^{36}$ OLIVEIRA, Julio Aguiar de. Interpretação do direito: entre a despedida do método e o improvável retorno da prudência. Argumenta Journal Law, Jacarezinho (PR), Brasil, n. 25. p. 171-190, jul./dez. 2016, p. 186.

${ }^{37}$ BODNAR, Zenildo. Os novos desafios da jurisdição para a sustentabilidade na atual sociedade de risco. Revista Veredas do Direito, Belo Horizonte, v. 6, n. 12, p. 101-119, jul./dez. 2009, p. 106.
} 
Santos, ainda, alerta que os profissionais tendem à lei do menor esforço no uso do direito jurisprudencial ${ }^{38}$. Deste modo, percebe-se que a superficialidade da fundamentação pode manifestar o subjetivismo do julgador, que baseia o seu julgamento em entendimentos particulares, as denominadas propensões cognitivas.

As propensões cognitivas do magistrado representam mais um obstáculo para o julgamento justo, eis que inviabilizam a neutralidade do julgador, representando verdadeiros ancoramentos cognitivos. Constata-se a existência de propensões do magistrado anteriores ao processo, como os preconceitos, e as propensões produzidas durante o processo, como a prova ilícita excluída do processo. O grande número de processos é um dos causadores da contaminação cognitiva do magistrado pela busca por mais agilidade do julgamento. Leia-se

Estudos empíricos (psicológicos e jurídicos), realizados com magistrados americanos, demonstram que o juiz sofre propensões cognitivas que o induzem a usar atalhos para ajudá-lo a lidar com a pressão da incerteza e do tempo inerentes ao processo judicial. É evidenciado que mesmo sendo experiente e bem treinado, sua vulnerabilidade a uma ilusão cognitiva no julgamento solitário influencia sua atuação $0^{39}$.

Theodoro Júnior e outros citam o exemplo do juiz que sofre uma espécie de bloqueio, tendo uma propensão de julgar improcedente o pedido se indeferiu uma liminar anteriormente ${ }^{40}$. Tal situação ocorre até mesmo se houver novas informações, pois o magistrado tende a reafirmar a decisão anterior.

Percebe-se assim que as propensões cognitivas são extremamente prejudiciais para o bom julgamento, e um dos meios para combater tal problema é o fomento ao debate, o contraditório, que inclusive pode diminuir as possibilidades de recursos.

\subsection{PSEUDOCOLEGIALIDADE}

A pseudocolegialidade representa mais um empecilho para o adequado uso dos precedentes que, como as propensões cognitivas, se justifica pelo expressivo

\footnotetext{
38 SANTOS, Carlos Maximiliano Pereira dos. Hermenêutica e aplicação do direito. Rio de Janeiro: Forense, 1993, p. 181 .

39 Segundo: GUTHRIE, Chris; RACHLINSKI, Jeffrey J., WISTRICH, Andrew J. Inside the judicial mind. Cornell Law Review, 777, p. 778-829, may 2001.

${ }^{40}$ THEODORO JÚNIOR, Humberto; et al. Op. cit., p. 97.
} 
número de processos nos tribunais. Tal fenômeno ocorre quando uma decisão que deveria ser proferida por um órgão colegiado é proferida pelo relator monocraticamente. Ou então, quando a decisão é originada de uma turma, mas em verdade é uma decisão do relator, pois os julgadores proferem a expressão "de acordo" dando a entender que não estão proferindo o voto depois de uma análise do caso. Essa sensação se evidencia quando se constata posicionamentos diversos do mesmo julgador em casos parecidos, sem questão que justifique a distinção entre os casos.

Esse fenômeno inevitavelmente causa instabilidade decisória em relação aos tribunais, problema que o CPC/2015 tenta combater em seus arts. 10 e 489, evidenciando a preocupação em relação à formação e aplicação dos precedentes. E ainda tentando prevenir a superficialidade da fundamentação na utilização dos precedentes.

\section{CONSIDERAÇÕES FINAIS}

No Brasil, constata-se um movimento de convergência entre as tradições do civil law e do commom law, causado pelo fortalecimento dos precedentes como fundamentação dos julgados. É relevante a distinção entre as Cortes Supremas e as Cortes de Justiça, com as funções de dar unidade e uniformizar o direito, respectivamente. $\mathrm{E}$ a distinção entre jurisprudência, súmula e precedente.

Percebe-se o papel fundamental da interpretação, tanto na formação quanto na aplicação dos precedentes, e a necessidade do uso adequado dos precedentes em harmonia com o princípio do contraditório, o dever de fundamentação, o princípio da colegialidade e a sustentabilidade jurisdicional. É de grande importância a utilização dos precedentes no ordenamento jurídico brasileiro, não apenas como meio para a duração razoável do procedimento, mas também para a indicação do entendimento correto para casos idênticos. Tal é essa importância que a existência de precedente contrário ao pedido é uma das causas para o julgamento liminar de improcedência.

Há ainda possibilidade de distinção e superação dos precedentes. E a modulação de efeitos para resguardar a segurança jurídica, caso ocorra revogação de um precedente.

Com advento do CPC/2015 se evidenciam a importância dos precedentes judiciais e a preocupação com o combate as condutas conflitantes com os princípios 
constitucionais. Faz-se imprescindível o respeito a estes princípios, que de maneira recorrente são infligidos, quais sejam, o princípio do contraditório, o dever de fundamentação e o princípio da colegialidade. A ofensa aos mesmos provoca problemas importantes e extremamente prejudiciais às partes e a toda sociedade. As dificuldades originadas pelo imenso número de demandas nos tribunais são prejudiciais para o bom julgamento. Tentar otimizar numericamente as decisões a qualquer custo apenas causa ainda mais obstáculos para o uso adequado dos precedentes, como a superficialidade da fundamentação, as propensões cognitivas e a pseudocolegialidade.

A título de resultados constatou-se que, de maneira recorrente, os precedentes são aplicados dissociados dos casos que lhes deram origem, sem reflexão e ausente a explicação sobre o motivo de sua incidência na hipótese. Isso ocorre devido aos comportamentos não cooperativos entre os sujeitos processuais, o subjetivismo muitas vezes presente nos magistrados e a tendência deles à facilitação dos julgamentos. Tal fenômeno é extremamente preocupante, pois são capazes de comprometer a justiça e, sobretudo, causar instabilidade decisória nos tribunais.

Tais problemas detêm solução no próprio CPC/2015, que estabeleceu os princípios a serem respeitados pelos sujeitos processuais. Quando as balizas legais forem verdadeiramente respeitadas e os sujeitos processuais agirem cooperando entre si, os resultados dos julgamentos então serão mais adequados. As práticas viciadas serão combatidas e se aprimorará a tutela jurisdicional no Brasil.

\section{REFERÊNCIAS}

BAHIA, Alexandre Melo Franco. As súmulas vinculantes e a nova escola da exegese. Revista de Processo, São Paulo, v. 206, p. 359-379, abr. 2012.

BODNAR, Zenildo. Os novos desafios da jurisdição para a sustentabilidade na atual sociedade de risco. Revista Veredas do Direito, Belo Horizonte, v. 6, n. 12, p. 101119, jul./dez. 2009. Disponível em: < http://www.domhelder.edu.br/revista/index. php/veredas/article/view/19> . Acesso em: 08 jan. 2018.

BRASIL. Constituição (1988). Constituição da República Federativa do Brasil. Brasília: Senado Federal, Centro Gráfico, 1988. 
BRASIL. Lei $\mathrm{n}^{\mathrm{0}}$ 13.105, de 16 mar. 2015. Código de Processo Civil. Diário Oficial da União, Brasília, 17 mar. 2015. Disponível em: < http://www.planalto.gov.br/ccivil_03/_ato2015-2018/2015/lei/113105.htm>.Acesso em: 01 nov. 2017.

EISENBERG, Melvin Aron. The nature of the common law. Cambridge, Mass, United States: Harvard University Press, 1991.

GOMES, Magno Federici; FERREIRA, Leandro José. A dimensão jurídico-política da sustentabilidade e o direito fundamental à razoável duração do procedimento. Revista do Direito, Santa Cruz do Sul, n. 52, v. 2, p. 93-111, maio/set. 2017. Disponível em: < https://online.unisc.br/seer/index.php/direito/article/view/8864>. Acesso em: 30 mar. 2018.

GORLA, Gino. Diritto comparato e diritto comune europeo. Milano: Giuffrè Editore, 1981.

GUTHRIE, Chris; RACHLINSKI, Jeffrey J., WISTRICH, Andrew J. Inside the judicial mind. Cornell Law Review, 777, p. 778-829, may 2001.

IOCOHAMA, Celso Hiroshi; BRUNO, Camila Kienen; BERGAMASCHI, Joice Duarte Gonçalves. O escopo educativo do processo e a educação da sociedade por meio da tutela jurisdicional. Revista Jurídica Cesumar, Maringa - PR, v. 17, n. 1, p. 11-41, jan./abr. 2017. Disponível em: <http://periodicos.unicesumar.edu.br/index.php/revjuridica/article/view/4368/29446> Acesso em: 12 jan. 2018.

MACCORMICK, Neil; SUMMERS, Robert S.; Introduction. In: MACCORMICK, Neil; SUMMERS, Robert S. Interpreting precedents: a comparative study. Aldershot: Ashgate, 1997. Cap. 1.

MARINONI, Luiz Guilherme; ARENHART, Sérgio Cruz; MITIDIERO, Daniel. Novo curso de processo civil: tutela dos direitos mediante procedimento comum. 2 . ed. São Paulo: Revista dos Tribunais, 2016. v. 2.

MOTTA, Otávio. Precedente e jurisprudência no estado constitucional brasileiro. In: MITIDIERO, Daniel (Coord.). O processo civil no Estado Constitucional. Salvador: Jus Podium, 2012. p. 263-320. 
NUNES, Dierle José Coelho. Processualismo constitucional democrático e o dimensionamento de técnicas para a litigiosidade repetitiva: a litigância de interesse público e as tendências 'não compreendidas' de padronização decisória. Revista de Processo, São Paulo, v. 199, nº 36, p. 41-82, set. 2011.

OLIVEIRA, Julio Aguiar de. Interpretação do direito: entre a despedida do método e o improvável retorno da prudência. Argumenta Journal Law, Jacarezinho (PR), Brasil, n. 25. p. 171-190, jul./dez. 2016. Disponível em:<http://seer.uenp.edu.br/ index.php/argumenta/article/view/861>. Acesso em: 12 jan. 2018

SANTOS, Carlos Maximiliano Pereira dos. Hermenêutica e aplicação do direito. Rio de Janeiro: Forense, 1993.

TARUFFO, Michele. Precedente e giurisprudenza. Rivista Trimestrale di Diritto e Procedura Civile, v. 61, n. 3, p. 709-725, set. 2007.

THEODORO JÚNIOR, Humberto et al. Novo CPC: fundamentos e sistematização. 2. ed. Rio de Janeiro: Forense, 2015.

TROCKER, Nicolò. Processo civile e costituzione. [s.l.]: A. Giuffrè, 1974.

Recebido em: 12 de fevereiro de 2018 Aceito em: 24 de julbo de 2018 